08

\title{
Влияние параметров метода PECVD на рост углеродных нанотрубок для устройств нанопьезотроники
}

\author{
(ㄱ Н.Н. Рудык, ${ }^{1}$ О.И. Ильин, ${ }^{1}$ М.В. Ильина, ${ }^{1}$ C.A. Хубежов, ${ }^{2}$ А.А. Федотов, ${ }^{1}$ O.A. Агеев ${ }^{1,3}$ \\ 1 Южный федеральный университет, Институт нанотехнологий, электроники и приборостроения, \\ 347922 Таганрог, Россия \\ ${ }^{2}$ Северо-Осетинский государственный университет им. К.Л. Хетагурова, \\ 362025 Владикавказ, Россия \\ ${ }^{3}$ Южный федеральный университет, НОЦ „Нанотехнологии“, \\ 347922 Таганрог, Россия \\ e-mail: nnrudyk@sfedu.ru, oiilin@sfedu.ru
}

Поступило в Редакцию 2 апреля 2021 г.

В окончательной редакции 2 апреля 2021 г.

Принято к публикации 2 апреля 2021 г.

Представлены результаты экспериментальных исследований влияния температуры роста и толщины каталитического слоя на геометрические и структурные параметры углеродных нанотрубок (УНТ). Показано, что применение подслоя на основе TiN позволяет обеспечить низкое удельное сопротивление при непосредственном выращивании УНТ на проводящем контакте. Установлено, что для формирования лучшего пьезоэлектрического отклика необходимо формировать наиболее дефектные УНТ. Показано, что степенью дефектности УНТ возможно контролируемо управлять в процессе их выращивания. Установлена связь между геометрическими и структурными параметрами УНТ, влияющими на пьезоэлектрический отклик. Показана потенциальная применимость УНТ для создания на их основе устройств нанопьезотроники (наногенераторов, нанохарвестеров энергии).

Ключевые слова: углеродные нанотрубки, PECVD, нанопьезотроника, пьезоэлектрический отклик, рамановская спектроскопия.

DOI: $10.21883 / J T F .2021 .10 .51365 .96-21$

\section{Введение}

C момента открытия углеродных нанотрубок (УНТ) [1] было показано, что они обладают уникальными механическими [2], температурными [3], химическими $[4,5]$ и электрическими $[6,7]$ свойствами. Возможность формирования переплетенных, а также вертикально ориентированных массивов с УНТ, обладающих малым радиусом острия и высоким аспектным отношением, делают их перспективными объектами для создания дисплеев $[8,9]$, источников рентгеновского излучения [10], устройств вакуумной микро- и наноэлектроники $[11,12]$. Кроме того, в 2017 г. была теоретически показана возможность формирования у УНТ аномальных пьезоэлектрических свойств [1315], которые в 2018 г. получили экспериментальное подтверждение [16,17]. Аномальные пьезоэлектрические свойства УНТ в совокупности с высокими значениями прочности и упругости открыли перспективы их применения в новой области электроники - нанопьезотроники [18]. Основной задачей нанопьезотроники является создание новых электронных устройств на основе пьезоэлектрических свойств наноструктур (наногенераторов, сенсоров, элементов памяти) [19-21].

Принцип работы таких устройств основан на формировании внутреннего электрического поля в деформированных наноструктурах, которое используется в каче- стве напряжения, управляющего транспортом носителей зарядов. При этом геометрические размеры УНТ, их плотность, ориентация по отношению к подложке, степень и тип дефектности [22-24] играют решающую роль при создании приборов и элементов нанопьезотроники. С точки зрения приборного применения и необходимости обеспечения низкого контактного сопротивления, перспективно выращивание УНТ непосредственно на контактных областях. Также важным параметром остается управление плотностью УНТ в массиве. Обеспечить данные требования позволяет метод плазмохимического осаждения из газовой фазы (PECVD). C его помощью возможно в широком диапазоне и с высокой точностью управлять температурой, давлением, потоками технологических газов и временем процесса. При этом сохраняется возможность направленного выращивания УНТ вдоль вектора напряженности электрического поля путем инициации плазмы $[16,25]$. Однако изменение даже одного технологического параметра влияет на свойства и геометрические размеры УНТ, что требует проведения и анализа большого объема экспериментальных исследований.

В настоящей работе исследовано влияние температуры роста УНТ и толщины каталитического слоя на геометрические и структурные параметры УНТ, выращенных методом PECVD, и проверена их потенциальная 


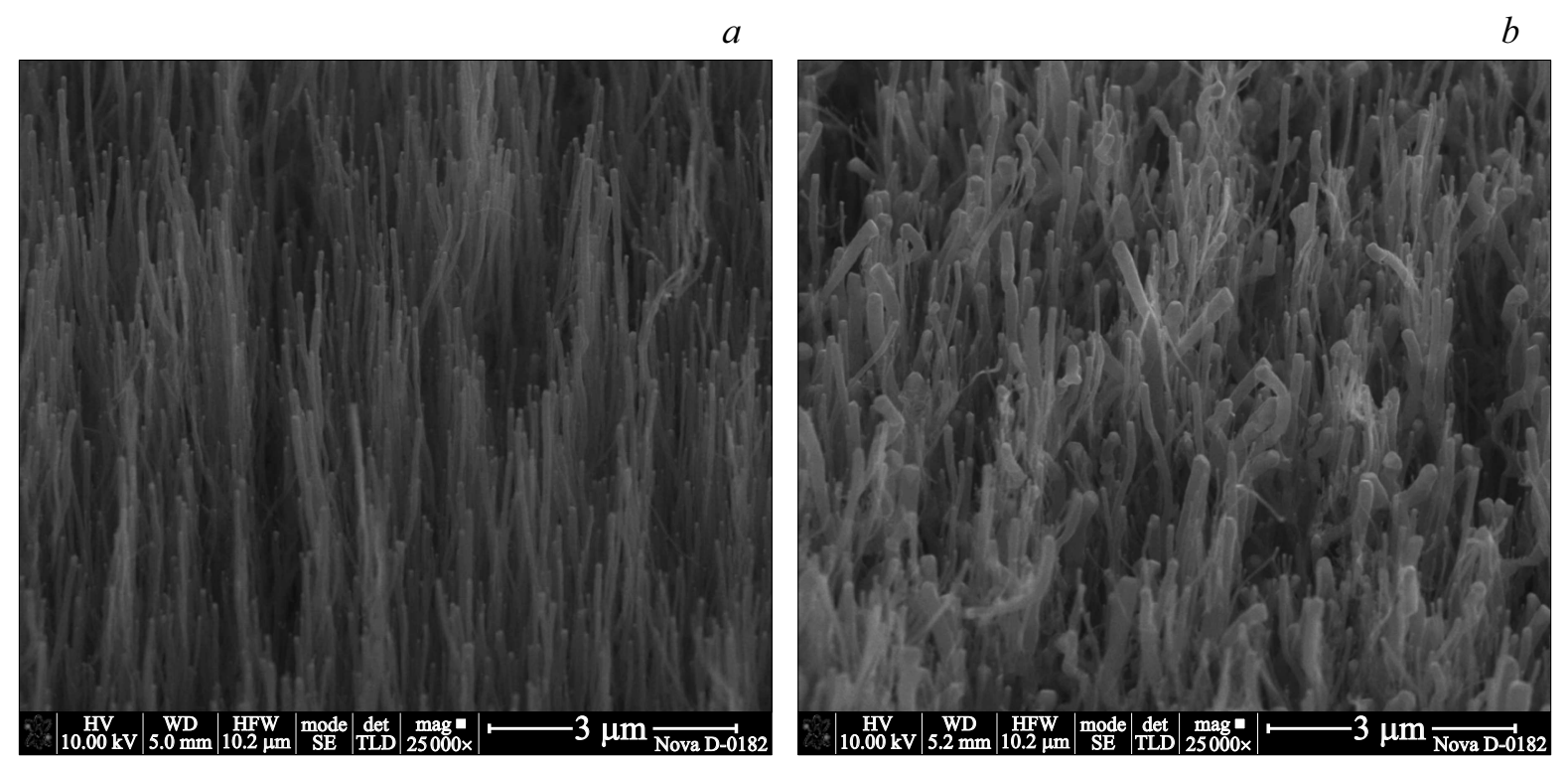

Рис. 1. РЭМ изображения массивов УНТ, полученных при: $a-$ температуре $645^{\circ} \mathrm{C}$ и толщине катализатора $15 \mathrm{~nm} ; ~ b-$ температуре $630^{\circ} \mathrm{C}$ и толщине катализатора $30 \mathrm{~nm}$.

применимость для создания устройств нанопьезотроники (наногенераторов, нанохарвестеров энергии).

\section{1. Описание эксперимента}

В качестве экспериментальных образов использовались подложки $p$ - $\mathrm{Si}(100)$, на поверхности которых методом магнетронного распыления на установке AUTO 500 (BOC Edwards, UK) формировалась пленка TiN толщиной $100 \mathrm{~nm}$, выступающая одновременно в качестве электропроводящего контактного слоя и диффузионного барьера между каталитическим слоем и подложкой. Затем проводилось напыление каталитического слоя $\mathrm{Ni}$ с толщинами в диапазоне от 5 до $30 \mathrm{~nm}$. Выращивание массивов вертикально ориентированных УНТ проводилось методом PECVD при диссоциации молекул ацетилена $\left(\mathrm{C}_{2} \mathrm{H}_{2}\right.$, поток $\left.70 \mathrm{sccm}\right)$ на поверхности каталитических центров (КЦ), образуемых в процессе отжига из сплошной пленки Ni катализатора. В процессе роста подавался вспомогательный газ аммиак $\left(\mathrm{NH}_{3}\right.$, поток $\left.210 \mathrm{sccm}\right)$, являющийся дополнительным источником водорода, связывающим аморфный углерод, a также выступающий в роли допирующей примеси азота, вносящей дефекты структуру УНТ. Время роста для всех процессов составляло $15 \mathrm{~min}$. Температура выращивания УНТ изменялась в диапазоне от 615 до $690^{\circ} \mathrm{C}$. В процессе роста инициировалась плазма на постоянном токе мощностью $40 \mathrm{~W}$. Полученные образцы исследовались методами растровой электронной микроскопии (РЭМ) на установке Nova Nanolab 600 (FEI, Нидерланды) и рамановской спектроскопии на установке Renishaw InVia Reflex (Renishaw plc, Великобритания) c длинной волны $514 \mathrm{~nm}$. Исследование внутренней структуры УНТ проводилось методом просвечивающей электронной микроскопии (ПЭМ) на установке Тесnаi Osiris (FEI).

Экспериментальные исследования пьезоэлектрического отклика экспериментальных образцов с УНТ выполнялись методом атомно-силовой микроскопии (АСM) с использованием ранее разработанной методики [16]. В качестве пьезоэлектрического отклика УНТ детектировался ток, возникающий в системе „нижний электрод/УНТ/зонд АСМ““ в результате деформации нанотрубок и формирования пьезоэлектрического потенциала под действием механического прижима зонда АCM к поверхности УНТ. Сила прижима $F$ изменялась от 0 до $1 \mu \mathrm{N}$. В качестве зонда АСМ использовался коммерческий кантилевер с платиновым покрытием марки NSG11/Pt.

\section{2. Обсуждение результатов}

Установлено, что подслой TiN позволяет обеспечить низкое контактное сопротивление $\left(0.1 \Omega \cdot \mathrm{cm}^{2}\right)$, которое не изменяется во всем диапазоне используемых температур и толщин катализатора. В результате статистической обработки РЭМ изображений выращенных массивов вертикально ориентированных УНТ (рис. 1), получены данные средней высоты УНТ от температуры роста и толщины каталитического слоя, которые сведены в таблицу. Для определения высоты УНТ образец раскалывался, помещался в камеру РЭМ Nova Nanolab 600, наклонялся на угол $52^{\circ}$, и контролировалась граница скола. Определение высоты проводилось с использованием встроенного (xtMicroscope Control) и дополнительного (Scandium v.5.0) программного обеспечения с учетом компенсации наклона образца. 
Зависимость высоты УНТ ( $\mu$ m) от температуры нагрева и толщины пленки катализатора

\begin{tabular}{c|c|c|c|c|c}
\hline \multirow{2}{*}{ Температура, ${ }^{\circ} \mathrm{C}$} & \multicolumn{5}{|c}{ Толщина катализатора, $\mathrm{nm}$} \\
\cline { 2 - 6 } & 5 & 10 & 15 & 20 & 30 \\
\hline 615 & $8.3 \pm 0.6$ & $19.7 \pm 1.0$ & $31.1 \pm 1.9$ & $26.4 \pm 1.1$ & $28.1 \pm 0.8$ \\
630 & $16.7 \pm 0.5$ & $24.2 \pm 0.6$ & $24.7 \pm 0.7$ & $33.1 \pm 0.8$ & $26.4 \pm 0.7$ \\
645 & $12.9 \pm 0.5$ & $21.5 \pm 0.9$ & $24.1 \pm 0.8$ & $31.5 \pm 0.7$ & $46.1 \pm 0.7$ \\
660 & $15.4 \pm 0.4$ & $19.1 \pm 0.8$ & $20.7 \pm 0.9$ & $22.2 \pm 1.3$ & $23.8 \pm 1.1$ \\
675 & $11.3 \pm 1.6$ & $18.0 \pm 0.9$ & $13.9 \pm 1.5$ & $19.6 \pm 1.4$ & $10.7 \pm 1.3$ \\
690 & $18.6 \pm 1.3$ & $22.6 \pm 1.6$ & $30.8 \pm 3.0$ & $43.0 \pm 1.5$ & $40.5 \pm 1.2$
\end{tabular}
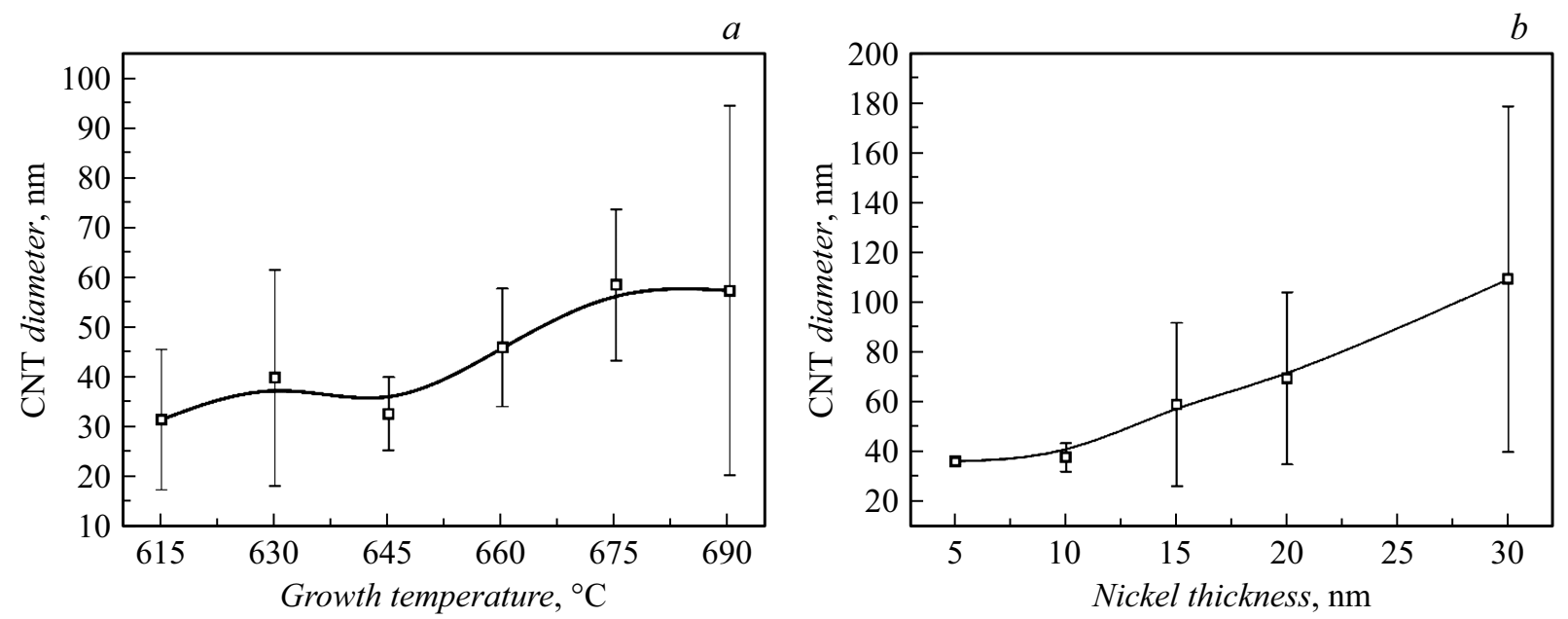

Рис. 2. Зависимость диаметра УНТ: $a$ - от температуры роста при толщине пленки катализатора $10 \mathrm{~nm} ; b-$ от толщины катализатора при температуре $645^{\circ} \mathrm{C}$.
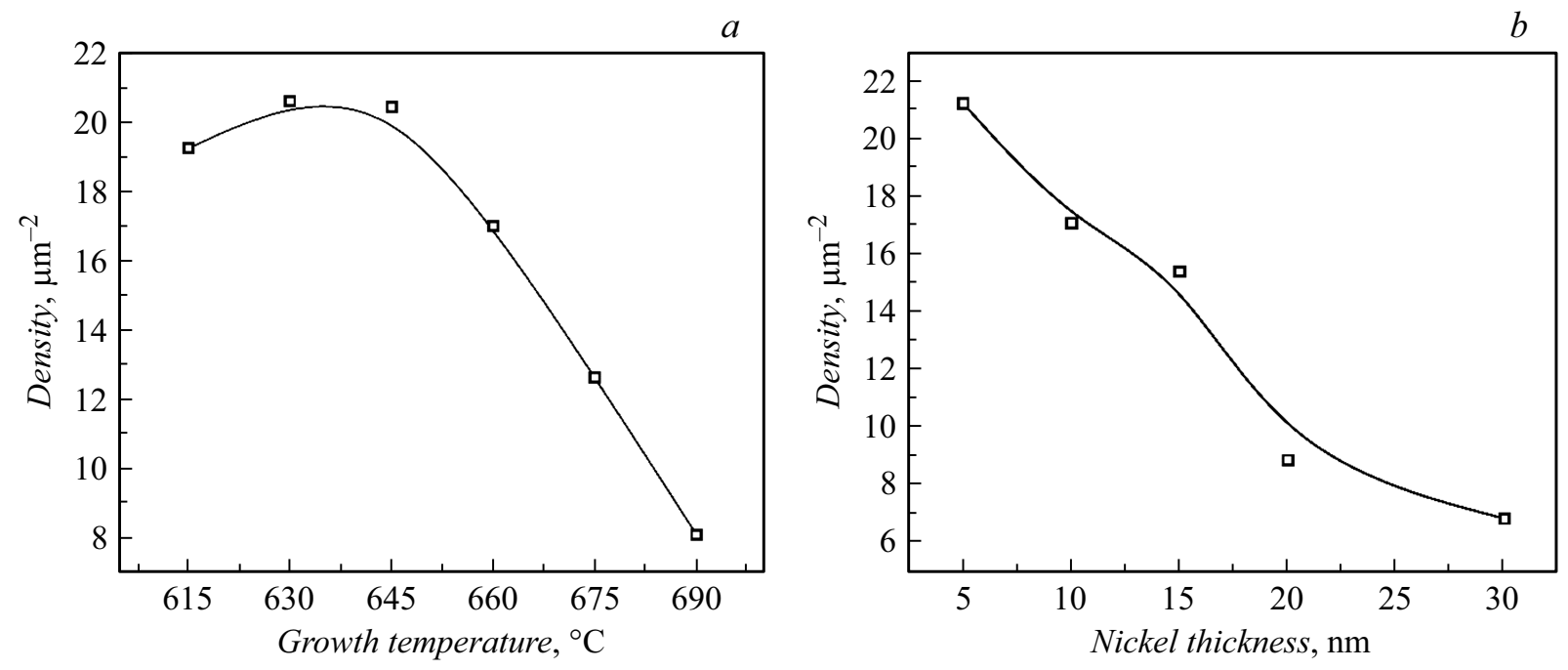

Рис. 3. Зависимость плотности УНТ в массиве: $a$ - от температуры роста при толщине пленки катализатора $10 \mathrm{~nm} ; b-$ от толщины пленки катализатора при температуре $660^{\circ} \mathrm{C}$.

Анализ данных показал, что высота УНТ увеличивается с ростом толщины каталитического слоя $\mathrm{Ni}$, достигая максимального значения $46.1 \pm 0.70 u$ m при температуpe $645^{\circ} \mathrm{C}$. Данная закономерность связана с формированием КЦ большего объема в процессе отжига каталити- ческой пленки большей толщины. КЦ большего объема позволяют разместить на своей поверхности большее число атомов углерода в результате разложения $\mathrm{C}_{2} \mathrm{H}_{2}$. Минимальное относительное отклонение высоты УНТ в массиве, определяемое как отношение стандартного 


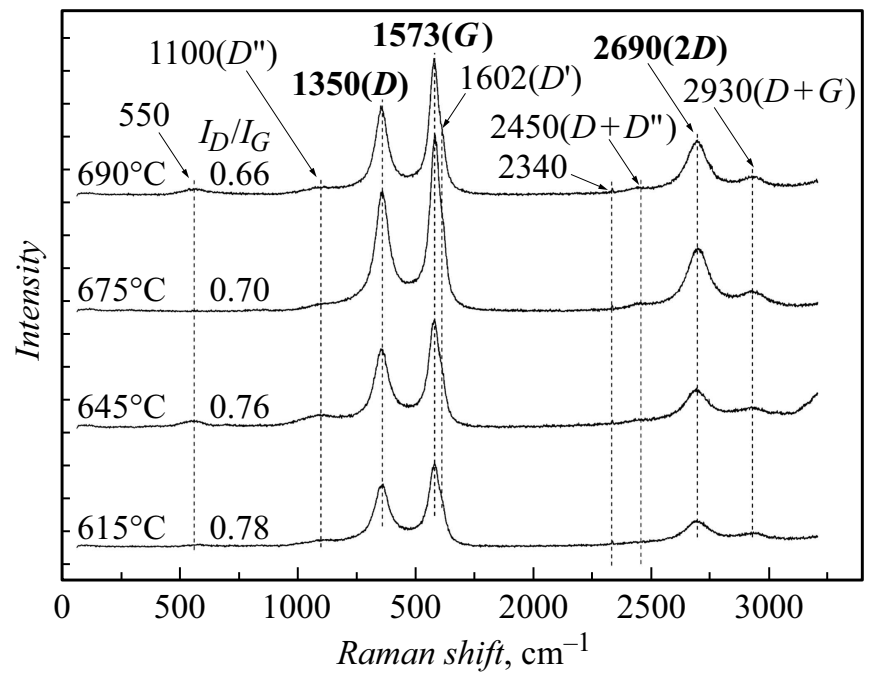

Рис. 4. Рамановские спектры образцов УНТ, выращенных при различной температуре.

отклонения к средней высоте УНТ, составило 1.5\% $\left(645^{\circ} \mathrm{C}\right.$, толщина пленки $\left.\mathrm{Ni} 30 \mathrm{~nm}\right)$, а максимальное $15 \%\left(690^{\circ} \mathrm{C}\right.$, толщина пленки $\left.\mathrm{Ni} 15 \mathrm{~nm}\right)$.

Было обнаружено, что диаметр УНТ увеличивается как при увеличении температуры роста (рис. 2,a), так и при увеличении толщины каталитического слоя (рис. 2,b), что также связано с увеличением объема КЦ в результате коалесценции и объединении мелких капель КЦ Ni в более крупные [17]. Диаметр УНТ увеличивается в диапазоне от 32 до $116 \mathrm{~nm}$, при этом также возрастает и стандартное отклонение диаметра (с 4 до $69 \mathrm{~nm}$ ). Минимальное относительное отклонение диаметра составило 4\% для образца, выращенного при температуре $645^{\circ} \mathrm{C}$ и толщине катализатора $5 \mathrm{~nm}$, а максимальное - $116 \%$ для $675^{\circ} \mathrm{C}$ и $30 \mathrm{~nm}$ соответственно.
Результаты экспериментальных исследований показали, что возможно управлять плотностью УНТ в массиве путем изменения температуры синтеза (рис. 3, $a$ ) и толщины каталитического слоя (рис. $3, b$ ). В зависимости от технологических параметров плотность УНТ в массиве изменялась в диапазоне от 1.4 до $31.6 \mu \mathrm{m}^{-2}$. При этом прослеживается корреляция между диаметром и плотностью УНТ, когда увеличение диаметра УНТ (вызванное как увеличением температуры, так и толщины каталитического слоя) приводит к уменьшению их плотности на образце.

С целью установления влияния технологических режимов на дефектность формируемых УНТ проводились исследования методом рамановской спектроскопии, которые показали наличие характерных $D$-, $G$-, $2 D$ - и $D+G$-пиков, соответствующих многостенным УНТ [21]. На рис. 4 приведены рамановские спектры для образцов с УНТ, выращенных при различных температурах на пленке Ni толщиной $30 \mathrm{~nm}$.

Оценка дефектности структур проводилась путем анализа отношения амплитуд $D$ - и $G$-пиков $\left(I_{D} / I_{G}\right)$ и показала уменьшение дефектности полученных УНТ с увеличением температуры роста (рис. 5,a) и толщины каталитического слоя (рис. $5, b)$.

Исследования, проведенные методом просвечивающей электронной микроскопии, показали наличие бамбукообразных перемычек (рис. 6) в структуре многостенных УНТ.

Можно предположить, что повышение температуры синтеза приводит к повышению поверхностной диффузии и, как следствие, лучшему упорядочению атомов углерода в графеновых листах, образующих УНТ. Также следует принять во внимание и то, что основной вклад в увеличение рамановской интенсивности $D$-пика и дефектности в целом вносят бамбукообразные перемычки внутри УНТ. При увеличении диаметра и соответственно
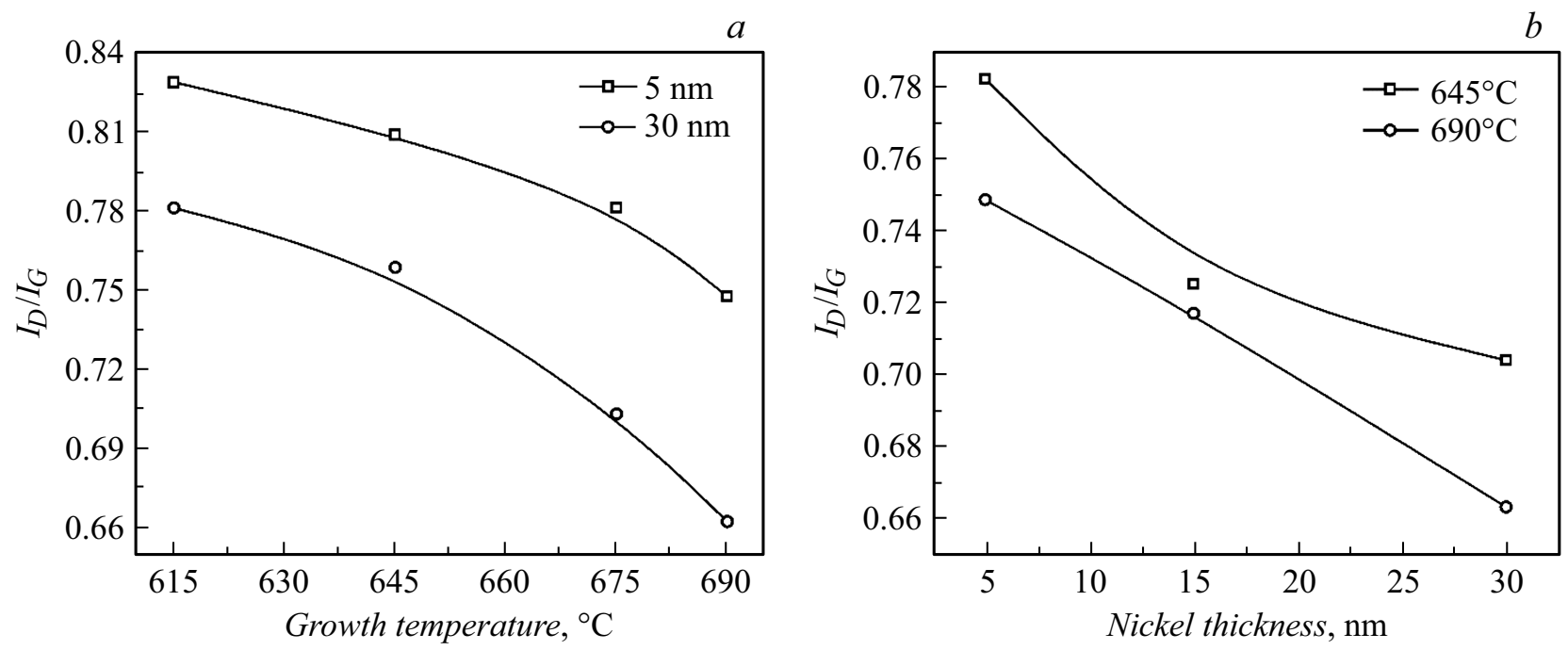

Рис. 5. Зависимость ID/IG образцов УНT: $a$ - от температуры роста; $b$ - от толщины пленки катализатора. 


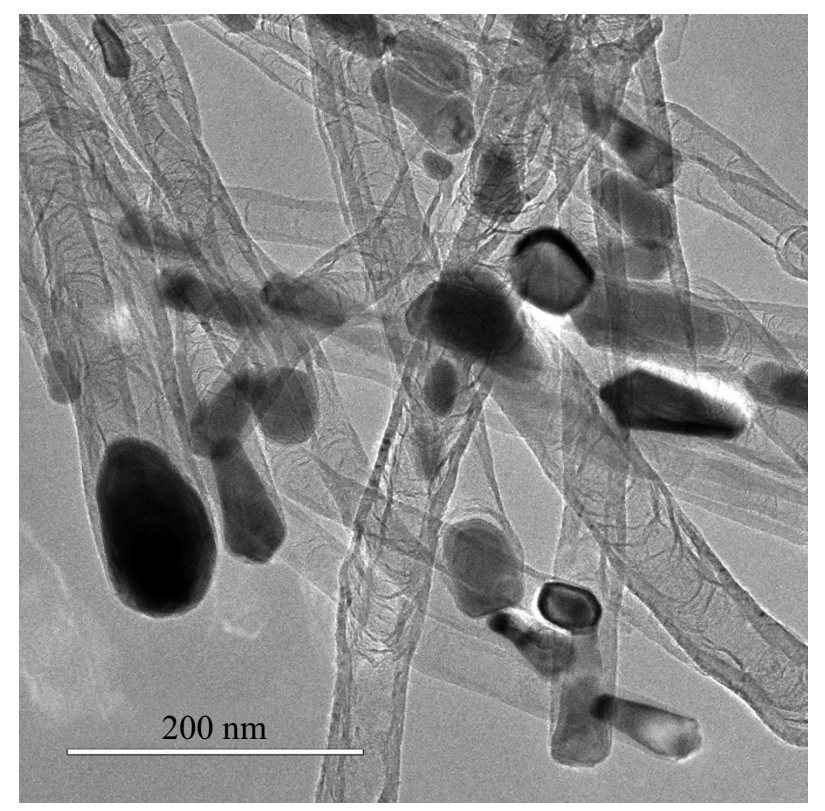

Рис. 6. ПЭМ изображение УНТ, выращенных при температуре $645^{\circ} \mathrm{C}$ и толщине пленки катализатора $15 \mathrm{~nm}$.

числа стенок УНТ часть сигнала комбинационного рассеяния может быть поглощена стенками многослойных УНТ и вызывать снижение амплитуды $D$-пика. Так, наименьшая дефектность $I_{D} / I_{G}=0.66$ наблюдалась для УНТ, выращенных при $690^{\circ} \mathrm{C}$ и толщине никеля $30 \mathrm{~nm}$. Наиболее дефектными $\left(I_{D} / I_{G}=0.84\right)$ оказались УНТ, полученные при $615^{\circ} \mathrm{C}$ и толщине никеля $5 \mathrm{~nm}$.

Структурное совершенство УНТ дополнительно оценивалось по величине полной ширины на полувысоте (FWHM) $D$ - (рис. 7, $a)$ и $G$-пиков (рис. 7, $b$ ), а также по положению данных пиков. Большое значение FWHM $D$ и $G$-пиков может быть связано с большим количеством слоев в УНТ.
Было обнаружено, что $G$-пик смещается к более высоким частотам с ростом температуры синтеза от 1573 до $1577 \mathrm{~cm}^{-1}$, при этом FWHM уменьшается с 71 до $58 \mathrm{~cm}^{-1}$. Смещение $G$-пика может быть вызвано изменением количества азотной примеси в структуре УНТ. Внедрение атомов примесей ведет к изменению концентрации электронов на поверхности УНТ, что отражается в изменении уровня Ферми и частоты $G$ пика $[22,23]$. Увеличение температуры роста также увеличивает частоту $D$-пика с 1346 до $1351 \mathrm{~cm}^{1}$. При этом $D$-пик сужается, а FWHM уменьшается с 87 до $69 \mathrm{~cm}^{-1}$. Более узкие характеристические пики свидетельствуют о более высокой структурной упорядоченности атомов в решетке УНТ [22].

Исследования пьезоэлектрического отклика экспериментальных образцов, выращенных при температуре $645^{\circ} \mathrm{C}$, показали уменьшение величины тока, генерируемого в процессе деформации УНТ, от -17 до $-12 \mathrm{nA} \mathrm{c}$ увеличением толщины каталитического слоя $\mathrm{Ni}$ от 5 до $30 \mathrm{~nm}$ (рис. 6). Как было показано ранее [16,26,27], генерация тока УНТ обусловлена процессом формирования пьезоэлектрического потенциала в процессе их деформации путем прижима зонда АСМ к их поверхности с силой $F$ (рис. $8, d)$.

Уменьшение величины генерируемого УНТ тока, вероятно, связано как с увеличением их диаметра (рис. $2, b$ ), так и с уменьшением дефектности УНТ при увеличении каталитического слоя никеля (рис. $5, b)$. Так, увеличение диаметра УНТ приводит к уменьшению кривизны ее поверхности и уменьшению поляризации, возникающей в результате ассиметричного перераспределения плотности электронов [27]. Кроме того, уменьшение диаметра УНТ приводит к увеличению их плотности в массиве, и, как следствие, повышению числа элеменов генерирующих ток, что является дополнительным приемущенством при формировании пьезоэлектрического наногенератора на их основе. Увеличение высоты УНТ
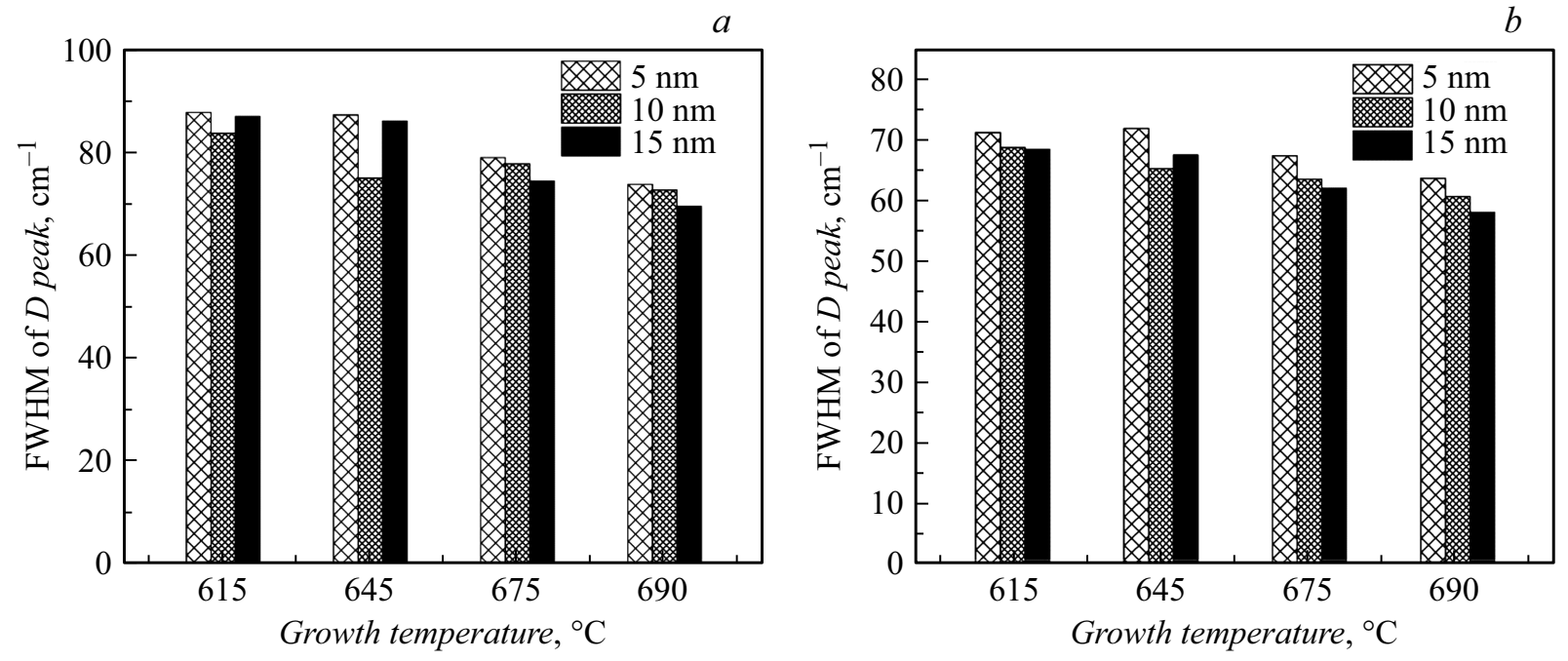

Рис. 7. Зависимость FWHM: $a-D$-пика; $b-G$-пика. 
$a$

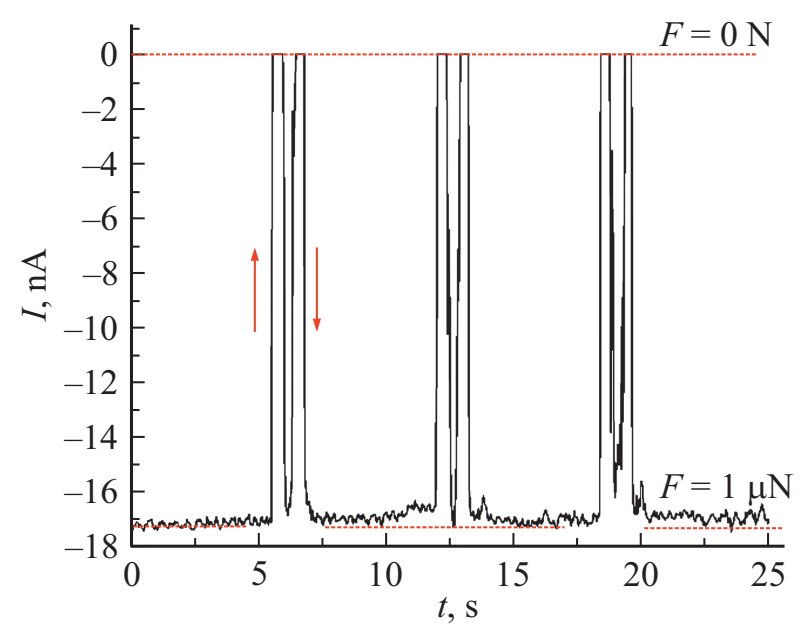

$c$

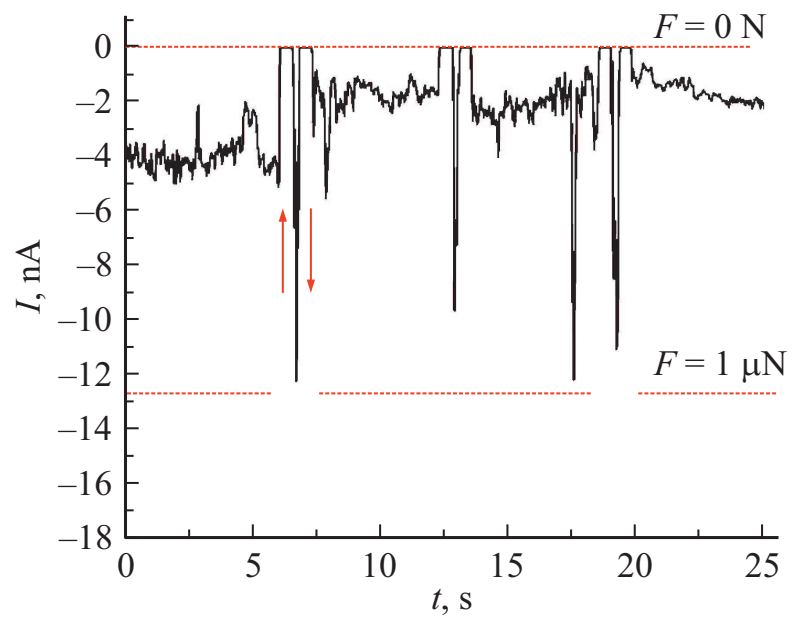

$b$
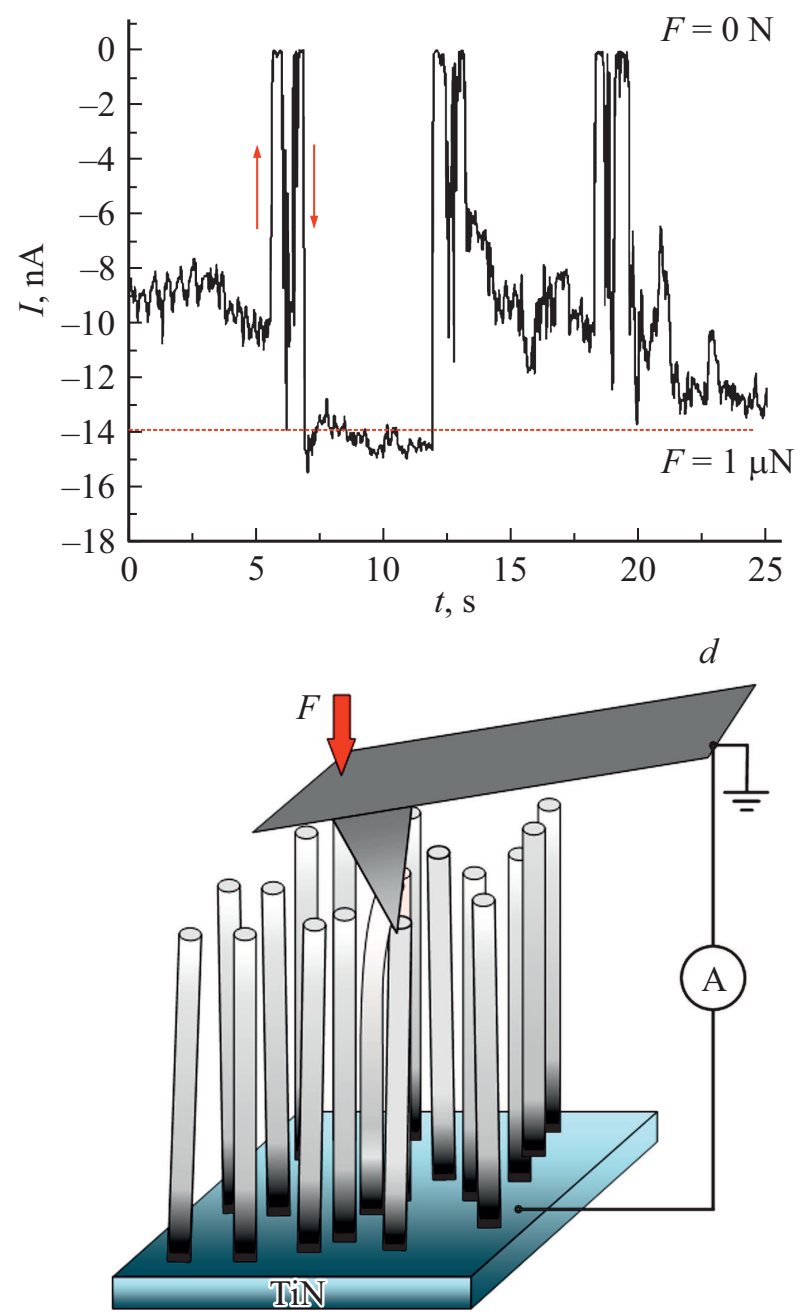

Рис. 8. Экспериментальные исследования пьезоэлектрического отклика массивов УНТ, выращенных при температуре $645^{\circ} \mathrm{C}$ и толщине каталитического слоя никеля: $a-5 \mathrm{~nm} ; b-15 \mathrm{~nm} ; c-30 \mathrm{~nm} ; d-$ схематическое изображение процесса измерения.

с увеличением толщины катализатора может использоватся как фактор, управляющий чувстительностью наногенератора. Более высокие УНТ будут лучше улавливать внешние колебания и вибрации, однако терять в величине создаваемого напряжения при внешнем воздействии одинаковой силы. При этом подслой ТiN устойчив к проведению процесса непосредственного выращивания УНТ на проводящем контакте и обеспечивает низкое контактное сопротивление. Таким образом, показано, что пьезоэлектрические свойства УНТ зависят от их геометрических параметров и дефектности, что может быть использовано для разработки перспективных элементов нанопьезотроники.

\section{Заключение}

В работе проведены результаты экспериментальных исследований влияния температуры роста УНТ и толщины каталитического слоя на геометрические и струк- турные параметры УНТ. Показана перспективность применения метода PECVD для контролируемого выращивания массивов вертикально ориентированных УНТ. Установлены закономерности влияния температуры роста УНТ и толщины каталитического слоя на диаметр, высоту и плотность нанотрубок в массиве. Показано, что применение подслоя на основе TiN позволяет обеспечить низкое удельное сопротивление, которое сохраняется при непосредственном выращивании УНТ на проводящем контакте. Установлено, что для формирования лучшего пьезоэлектрического отклика необходимо формировать наиболее дефектные УНТ. Показано, что степенью дефектности возможно контролируемо управлять в процессе выращивания УНТ. Установлена связь между геометрическими и структурными параметрами УНТ, влияющими на пьезоэлектрический отклик. Проверена потенциальная применимость УНТ для создания на их основе устройств нанопьезотроники (наногенераторов, нанохарвестеров энергии). 


\section{Благодарности}

Коллектив авторов благодарит заведующую кафедрой „Нанотехнология“ ЮФУ А.Г. Разумную и научного сотрудника ЮНЦ РАН Н.В. Лянгузова за помощь в проведении исследований методом рамановской спектроскопии.

\section{Финансирование работы}

Исследование влияния режимов выращивания на структуру и геометрические параметры УНТ выполнено при финансовой поддержке Российского фонда фундаментальных исследований (проект № 20-37-70034). Исследование влияния толщины каталитического слоя $\mathrm{Ni}$ на пьезоэлектрический отклик выполнено при поддержке Российского научного фонда (проект № 20-7900284).

\section{Конфликт интересов}

Авторы заявляют, что у них нет конфликта интересов.

\section{Список литературы}

[1] S. Iijima. Nature, 354, 56 (1991).

[2] L. Yang, I. Greenfeld, H.D. Wagner. Sci. Adv., 2 (2), e1500969 (2016). DOI: $10.1126 /$ sciadv.1500969

[3] M. Ahmad, S.R.P. Silva. Carbon, 158, 24 (2020). DOI: 10.1016/j.carbon.2019.11.061

[4] K.E. Moore, D.D. Tune, B.S. Flavel. Adv. Mater., 27, 3105 (2015). DOI: 10.1002/adma.201405686

[5] R. Tang, Y. Shi, Z. Hou, L. Wei. Sensors, 17, 882 (2017). DOI: $10.3390 / \mathrm{s} 17040882$

[6] C. Biswas, Y.H. Lee. Adv. Function. Mater., 21, 3806 (2011). DOI: $10.1002 / \mathrm{adfm} .201101241$

[7] J.-C. Charlier, J.-P. Issi. Appl. Phys. A, 67, 79 (1998).

[8] K. Jiang. Micro and Nano Technologies, 2017. DOI: 10.1016/B978-0-323-41481-4.00004-6

[9] X. Liang, J. Xia, G. Dong, B. Tian, L. Peng. Topics in Current Chem., 374, 80 (2016). DOI: 10.1007/s41061-016-0083-6

[10] R.J. Parmee, C.M. Collins, W.I. Milne, M.T. Cole. Nano Convergence, 1, 34 (2014). DOI: 10.1186/s40580-014-0034-2

[11] M.M. Shulaker, G. Hills, R.S. Park, R.T. Howe, K. Saraswat, H.-S.P. Wong, S. Mitra. Nature, 547, 74 (2017). DOI: 10.1038/nature22994.

[12] G.J. Brady, A.J. Way, N.S. Safron, H.T. Evensen, P. Gopalan, M.S. Arnold. Sci. Adv., 2 (9), e1601240 (2016). DOI: $10.1126 /$ sciadv.1601240

[13] M.V. Ilina, Yu.F. Blinov, O.I. Il'in, N.N. Rudyk, O.A. Ageev. IOP Conference Series: Mater. Sci. Eng., 256 (1), 012024 (2017). DOI: 10.1088/1757-899X/256/1/012024

[14] D. Hu, M. Yao, Y. Fan, C. Ma, M. Fan, M. Liu. Nano Energy, 55, 288 (2019). 10.1016/j.nanoen.2018.10.053

[15] S.I. Kundalwal, S.A. Meguid, G.J. Weng. Carbon, 117, 462 (2017). DOI: 10.1016/j.carbon.2017.03.013

[16] M.V. Il'ina, O.I. Il'in, Y.F. Blinov, A.A. Konshin, B.G. Konoplev, O.A. Ageev. Mater., 11 (4), 638 (2018). DOI: $10.3390 / \mathrm{ma} 12010165$
[17] Нанотехнологии в микроэлектронике, под ред. О.А. Агеева, Б.Г. Коноплева (Наука, М., 2019) ISBN: 978-5-02-040201-0

[18] Z.L. Wang. Adv. Mater., 19 (6), 889 (2007). DOI: 10.1002/adma.200602918

[19] Z.L. Wang. Nano Today. Elsevier Ltd, 5 (6), 540 (2010). DOI: 10.1016/j.nantod.2010.10.008

[20] Z.L. Wang. Adv. Mater., 24 (34), 4632 (2012). DOI: $10.1002 /$ adma.201104365

[21] X. Wen. Nano Energy. Elsevier, 14, 276 (2014). DOI: $10.1002 /$ inf 2.12079

[22] A.C. Ferrari. Solid State Commun., 143, 47 (2007). DOI: $10.1016 /$ j.ssc.2007.03.052

[23] M. Lazzeri, F. Mauri. Phys. Rev. Lett., 97, 266407 (2006). DOI: 10.1103/PhysRevLett.97.266407

[24] B.G. Sumpter, V. Meunier, J.M. Romo-Herrera, E. Cruz-Silva, D.A. Cullen, H. Terrones, D.J. Smith, M. Terrones. ACS Nano, 1 (4), 369 (2007). DOI: 10.1021/nn700143q

[25] S. Hofmann, C. Ducati, J. Robertson. Appl. Phys. Lett., 83, 135 (2003). DOI: 10.1063/1.1589187

[26] Z. Ren, Y. Lan, Y. Wang. Aligned Carbon Nanotubes (Springer). DOI: 10.1007/978-3-642-30490-3

[27] S.I. Kundalwal, S.A. Meguid, G.J. Weng. Carbon, 117, 462 (2017). DOI: 10.1016/j.carbon.2017.03.013 